\title{
Adecuación del viaducto ferroviario de Serín como pasarela peatonal
}

\author{
Valentín Arrieta Berdasco \\ Dr. Arquitecto
}

\section{RESUMEN:}

El proyecto ejecutado recupera un tramo de vía ferroviaria abandonada durante décadas en la parroquia de Serín (Gijón). Parte de dicha vía discurre por un viaducto del siglo XIX que es acondicionado como pasarela peatonal salvando la barrera física que supone la autopista, y que hasta ese momento dificultaba enormemente la conexión entre los distintos barrios. El nuevo objeto arquitectónico se inspira en la configuración del viejo puente, y su diseño se integra en él. Con esta intervención se recupera un elemento patrimonial de gran importancia al mismo tiempo que se proporciona a los vecinos un paso seguro sobre la autopista.

\section{PALABRAS CLAVE:}

Serín, viaducto, pasarela, peatonal, acero.

\section{ABSTRACT:}

The project recovered a stretch of train tracks abandoned for decades in Serín (Gijón). Part of this track runs along a viaduct of the 19th century that is conditioned as a pedestrian walkway saving the physical barrier of the motorway, which hindered the connection between some neighborhoods. The new architectural object is inspired by the old bridge configuration, and its design is integrated into it. This intervention recovers an important heritage element and provides to the neighbors a safe passage above the motorway.

\section{KEYWORDS:}

Serin, viaduct, walkway, pedestrian, Steel. 


\section{Emplazamiento}

Serín es una parroquia de Gijón situada en el vértice suroccidental del concejo, por cuyo territorio discurren desde hace muchos años algunas de las vías de comunicación más importantes del centro de la región, ya que en este punto se proyectó el nudo de autopistas que conectan las importantes localidades de Oviedo, Avilés y Gijón, conocida popularmente como autopista "Y". Anteriormente, por esta zona fue trazada la línea ferroviaria que une Gijón con Oviedo, y posteriormente con la Meseta a través del puerto de Pajares.

La línea ferroviaria fue construida a finales del siglo XIX por la Compañía de Ferrocarriles del Noroeste de España, contando con una estación terminal en Gijón, conocida como la Estación del Norte, actual Museo del Ferrocarril de Asturias. En la parroquia de Serín se levantó una estación en torno a la que giró la vida del lugar hasta hace algunas décadas, contando con una importante actividad mercantil y de tránsito de pasajeros. A los pocos metros de salir de la estación en dirección a Oviedo, se construyó un viaducto para salvar una gran vaguada denominada La Vega, por la que actualmente discurre la mencionada autopista, la cual pasa por debajo de los arcos del viaducto. Dicho elemento, conocido como Viaducto de Belescún, forma parte del trazado original de la vía, y se construyó en 1873, cayendo en desuso en 1978 al construirse paralelamente, a doscientos metros, un nuevo viaducto que permitía el paso de doble vía, algo que imposibilitaba la estrechez del primigenio puente.

\section{Descripción del viaducto y estado previo}

El viaducto cuenta con una longitud de 178,5 metros y un ancho de 4,8 metros. Su construcción está realizada con piedra caliza con sillares almohadillados en algunas zonas, y se compone de once arcos de 13,4 metros de luz, y una altura máxima de 18 metros. Seis de estos arcos actualmente están atravesados por vías rodadas.

Antes de acometer las obras de rehabilitación y adecuación del viaducto, éste había permanecido abandonado durante más de treinta años, al igual que un tramo previo y posterior de la antigua vía, existiendo incluso dificultad para acceder a él debido a la maleza acumu- lada. A pesar de ello, no presentaba daños de importancia, siendo las patologías existentes producto de su escaso mantenimiento. La plataforma del viaducto se encontraba desprovista de la antigua vía, aunque acumulaba todavía abundante zahorra.

\section{Objetivos de la intervención}

La adecuación del viejo viaducto venía a solucionar una antigua reivindicación de los vecinos de Serín, que veían dividida su parroquia por la interposición de la barrera física que suponía la autopista. Ésta dificultaba enormemente la comunicación peatonal entre los distintos barrios, existiendo un largo y tortuoso paso por debajo de la autopista que en época de lluvias se volvía impracticable. Hay que tener en cuenta, que muchos vecinos de los barrios de El Gallinal, El Peridiellu y El Campozón, tenían que atravesar dicho paso peatonal para ir a la estación de tren, situada en el barrio de L'Espín. Debido a las dificultades de este trayecto, algunos de ellos atravesaban por el viejo viaducto ferroviario a pesar de no contar con ningún tipo de protección ni del firme adecuado, con el peligro que ello suponía.

Gracias al acuerdo alcanzado por ADIF y el Ayuntamiento de Gijón, se consiguió la cesión municipal del viaducto y de los tramos de vía que permanecían abandonados antes y después de él, con el objetivo de realizar una nueva senda de uso peatonal que conectase de manera directa y segura las dos partes de la parroquia hasta entonces divididas.

Para ello fue necesario realizar un acondicionamiento total de la vieja caja por la que circulaban los trenes, desbrozándola y limpiándola, colocando un nuevo firme de hormigón HM-25 de $15 \mathrm{~cm}$. de espesor sobre base de material granular. En total, se adecuó una longitud de 778 metros, que posteriormente fueron ampliados con otros 587 metros, conformando de esta manera una senda peatonal que ya no sólo es utilizada por los vecinos, sino que es un atractivo más de la parroquia, atrayendo a numerosos visitantes y senderistas que disfrutan de ella especialmente durante los fines de semana.

El tramo de esta senda peatonal que atraviesa el antiguo viaducto ferroviario se resolvió mediante la construcción de una pasarela semicubierta cuyo objetivo era la de propor- 


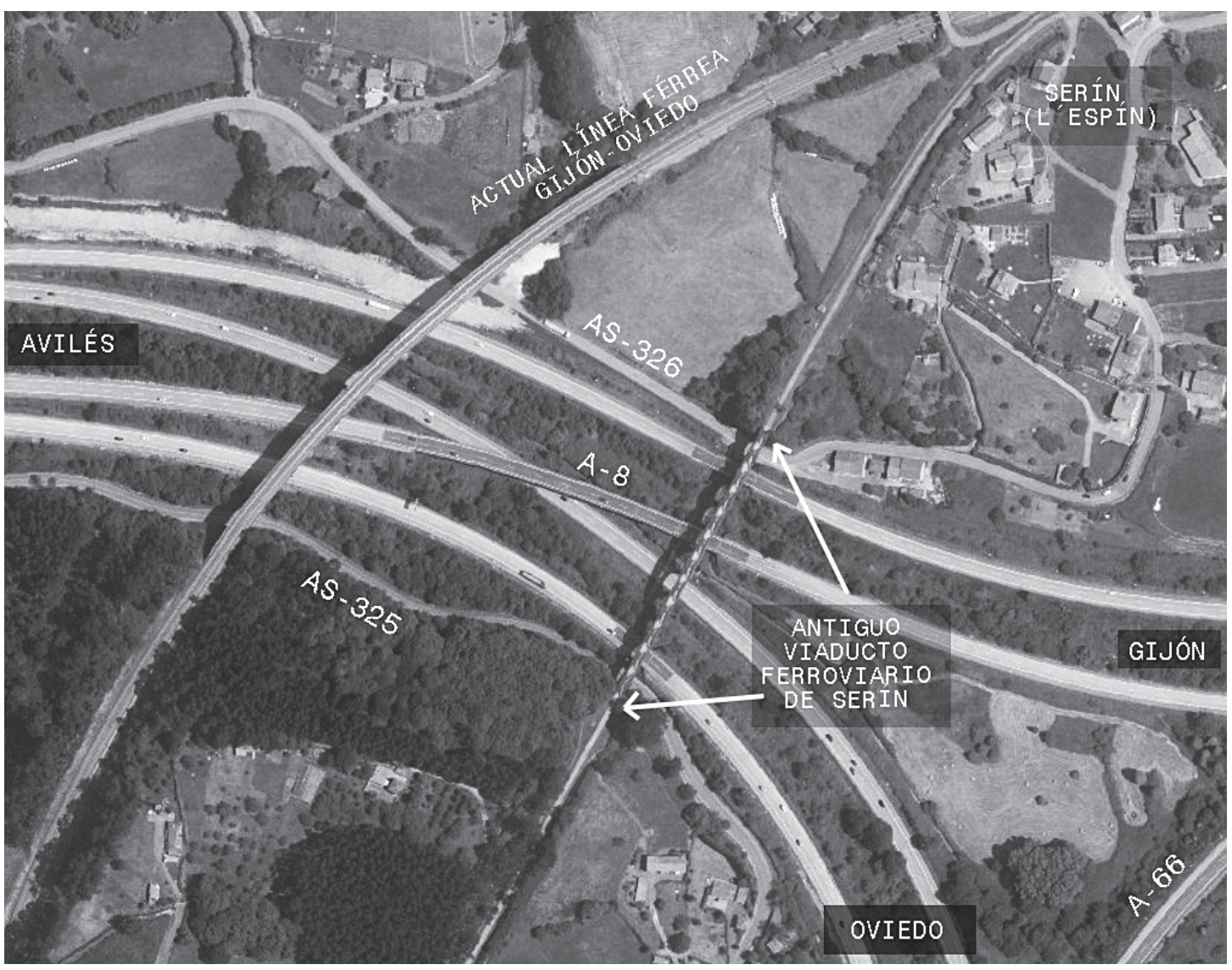

Fig. 1. Vista aérea de la zona donde se ubica el viaducto, con indicación de las principales vías de comunicación.

cionar seguridad a los viandantes, ya que la gran altura del puente y la "agresividad" del entorno en este punto (debido al paso de la autopista bajo él), hacían del viaducto un paso especialmente desagradable y peligroso para el tránsito peatonal, a pesar del acondicionamiento del firme. Ante todo, se pretendía evitar la caída de objetos y personas a la autopista, así como conformar un espacio de tránsito más "amable", correctamente iluminado y donde el agua de lluvia fuese canalizada para evitar encharcamientos de la nueva vía peatonal.

\section{Diseño propuesto}

La nueva estructura se proyecta como pieza integrada tanto en el entorno como en el propio puente y con un marcado carácter ferroviario e industrial que hace referencia a la antigua función de este viaducto (algo que queda patente en la elección de los materiales), pero sin renunciar a un lenguaje arquitectónico contemporáneo.
La pieza se estructura a partir de doce módulos que emulan un encadenamiento de vagones de tren, formados por arcos laterales que se intercalan con los del puente, integrándose perfectamente al mantener su misma luz y ritmo, y otros arcos diagonales que rigidizan el módulo y sirven de apoyo al cerramiento superior. La transparencia de los cerramientos laterales de mallas metálicas (necesarios por seguridad) hacen más ingrávida la pieza sobre el puente, completando la composición del mismo sin dotarlo de demasiada presencia ni competir con él, hecho que se ve reforzado por el contraste entre pesadez y ligereza de ambos elementos.

Junto a estos arcos laterales, el otro elemento que caracteriza y define el volumen es la catenaria, clara referencia al pasado ferroviario. Una catenaria es la curva que adoptaría por la acción de la gravedad un cable pesado y perfectamente flexible colgado entre dos soportes. Este cable genera por revolución un paraboloide hiperbólico de tela metálica que junto al cerramiento de chapa corten define y cierra el espacio, manteniendo cierta transparencia al mismo tiempo que protege al viandante. 
Los materiales y técnicas constructivas utilizadas en la construcción de la pasarela pretenden favorecer su integración en el puente haciendo referencia a la industria asturiana, tan importante en el triángulo geográfico que forman Gijón, Oviedo y Avilés. La utilización de materiales de fabricación local, presentándose de forma pura (con escaso tratamiento) y con posibilidad de fácil montaje (acero galvanizado, acero corten, malla metálica, cables de acero...) refuerzan esta idea.

De esta manera, el acero se convierte en el gran protagonista, utilizado con diferentes tratamientos de protección en función de la posición y misión de cada elemento (acero corten, galvanizado o inoxidable), pretendiendo con ello reducir costes de mantenimiento en un entorno agresivo.

Por otra parte, la pasarela pretende ser un elemento simbólico, integrado pero contemporáneo, que complete la composición de esta gran puerta de entrada al concejo de Gijón desde el occidente asturiano y Galicia. Por debajo de este viaducto circulan diariamente miles de personas convirtiéndose en el primer elemento característico del concejo. La composición escultórica del conjunto, su privilegiada situación y calidad arquitectónica hacen de este elemento un buen cartel de bienvenida a nuestra ciudad.

\section{Ejecución}

La ejecución fue pensada para ser realizada sin necesidad de colocar medios auxiliares difícilmente compatibles con el mantenimiento de la circulación por las vías rodadas que pasan por debajo del viaducto, garantizando además unas condiciones de máxima seguridad para evitar la caída de objetos a dichas vías. Para ello se diseñó una estructura, en colaboración con INFAT Ingeniería, Formación y Asesoramiento Técnico, pensada para ser parcialmente ensamblada en taller, evitando además las soldaduras en obra. Los módulos estructurales se llevaron a obra parcialmente montados, con perfiles tubulares de acero galvanizado SHS-140x5 con extremos preparados para ser machihembrados en obra, asegurando estas uniones con tornillería, y sellándolas para proteger la unión.

Los vanos laterales se cerraron con malla electrosoldada galvanizada de $150 \times 150$ milímetros, con diámetro de barra de 5 milímetros, soldada a unos pies derechos formados por perfiles angulares de acero galvanizado.

Los módulos estructurales se cubrieron parcialmente con "gajos" de acero corten a los que se le soldaron unos cordones metálicos en los laterales para conducir el agua caída sobre ellos hacia la base de los arcos, evitando la escorren-

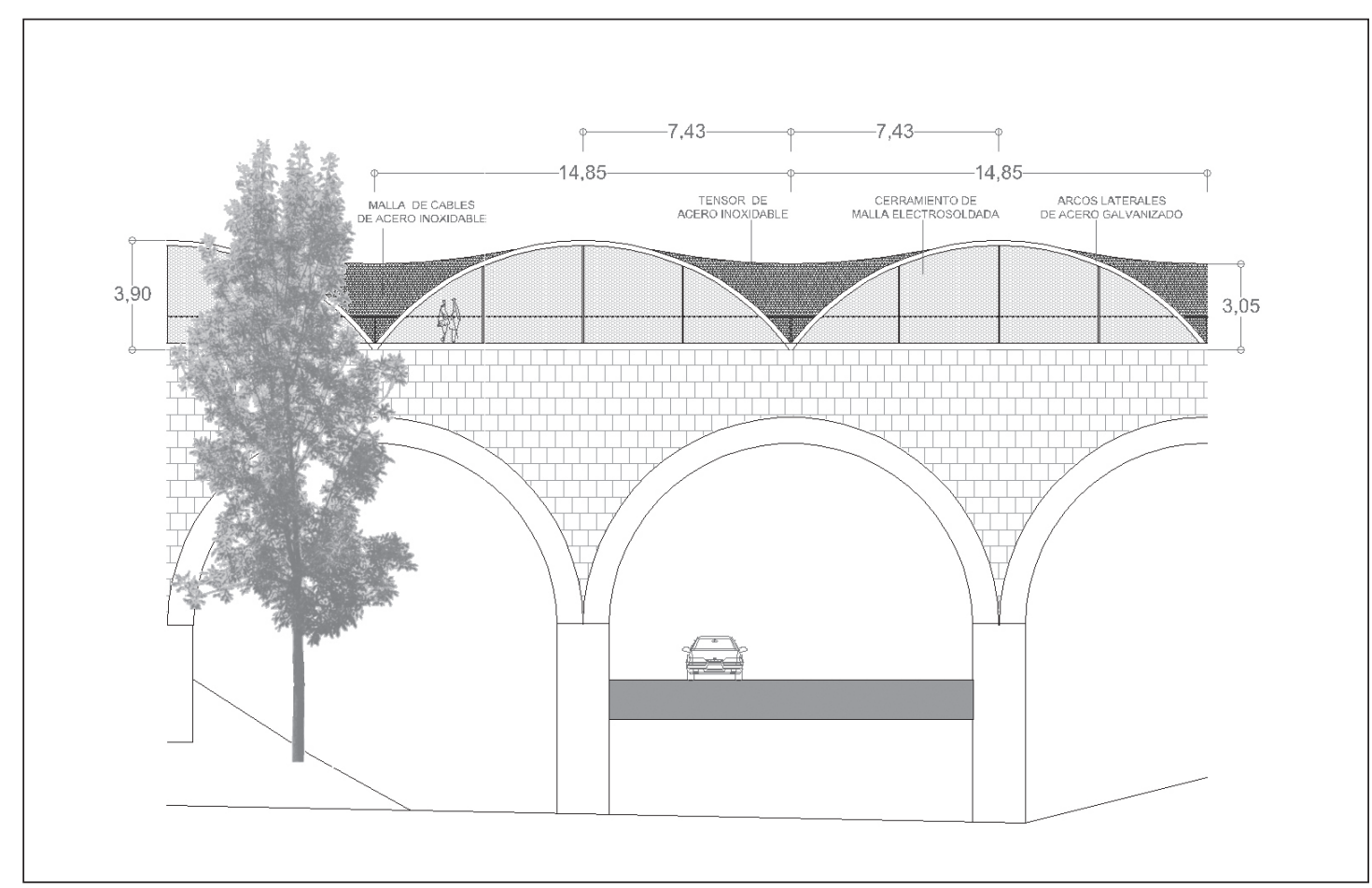

Fig. 2. Alzado parcial del viaducto con la nueva pasarela peatonal construida sobre él. 
tía de agua con restos de oxidación hacia los elementos estructurales de acero galvanizado. El acero corten se colocó sin tratamiento adicional, desechando la opción de aplicar barnices que impidan su oxidación. Gracias a ello, adquiere una rica variedad de tonalidades en función del tipo de luz y de la presencia o no de agua.

Finalmente, el espacio entre módulos fue cerrado mediante la colocación de paraboloides hiperbólicos de malla de cables de acero inoxidable X-TEND generados por revolución a partir de cables tensores de acero inoxidable, adaptándose a la forma deseada.

Una sencilla barandilla tubular de acero galvanizado ayuda a delimitar el paso alejando al peatón de los bordes del camino, donde la altura libre es menor debido a la disposición de los arcos diagonales que forman, junto a los laterales, el módulo estructural básico, generador de una interesante secuencia espacial al repetirse doce veces.

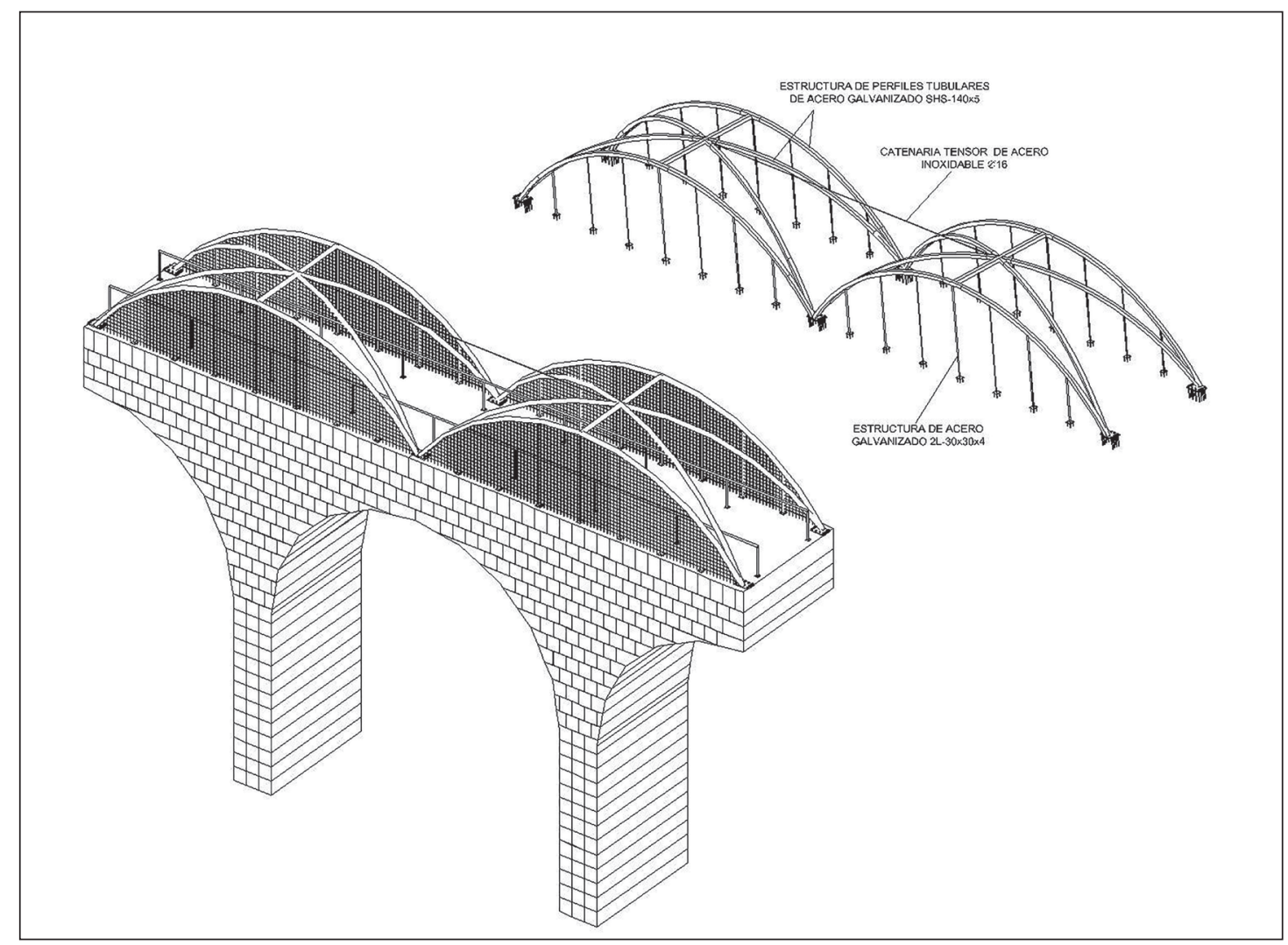

Fig. 3. Esquema estructural de los módulos que componen la pasarela peatonal.

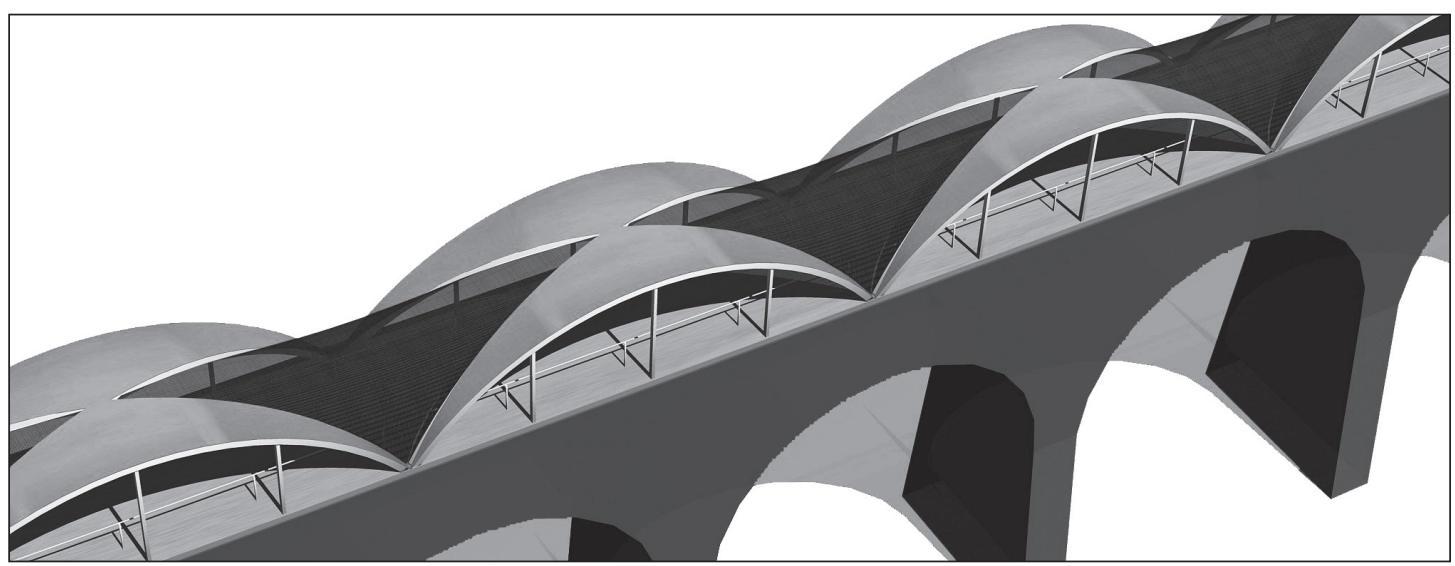

Fig. 4. Infografía previa al proyecto, donde se aprecia la composición general de la pasarela, y la relación con el antiguo viaducto ferroviario. 


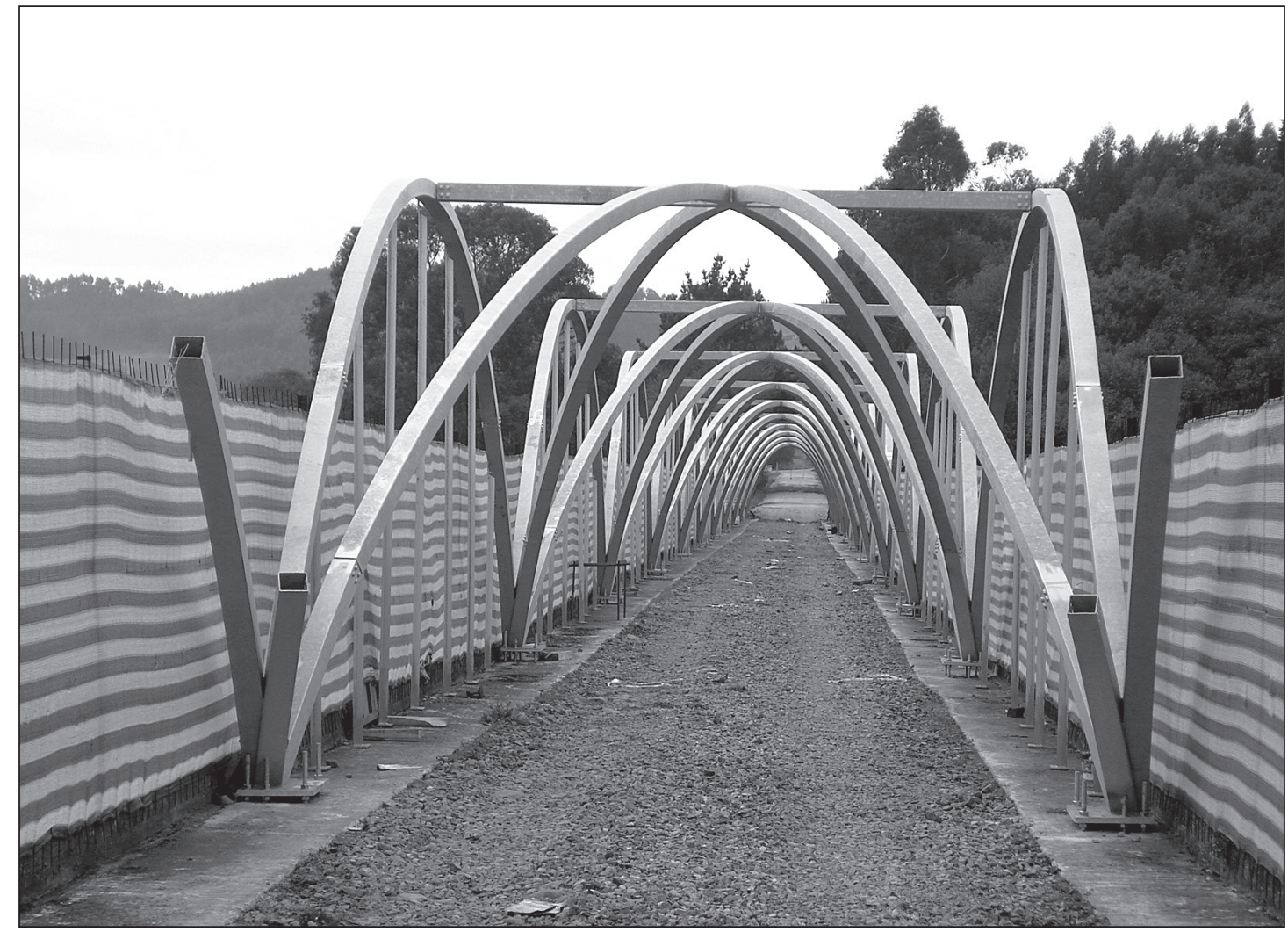

Fig. 5. Fotografía de obra durante el montaje de la estructura primaria de acero galvanizado.

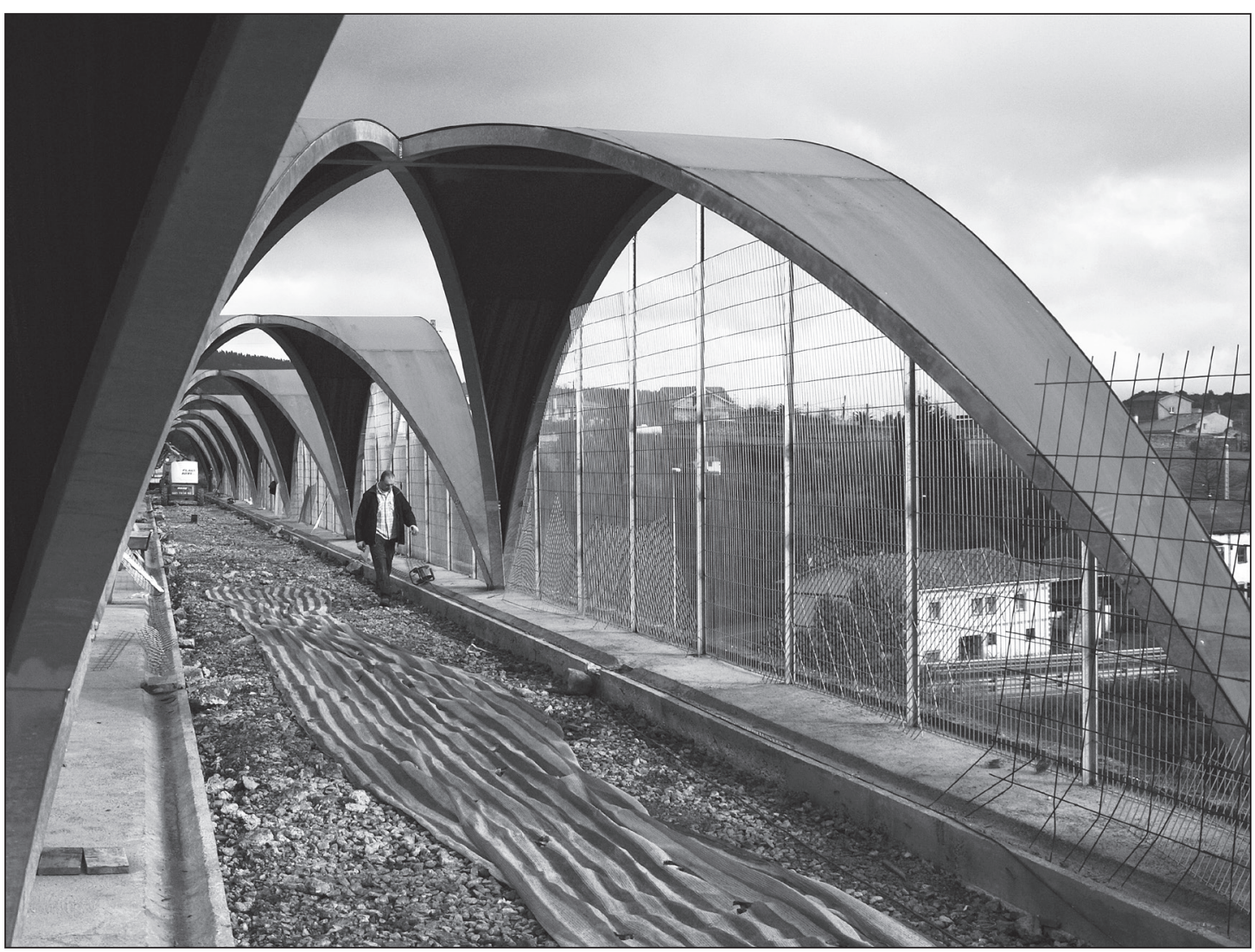

Fig. 6. Fotografía de obra con el cerramiento superior de chapa de acero corten colocado, y el cerramiento lateral de malla electrosoldada en fase de colocación. 


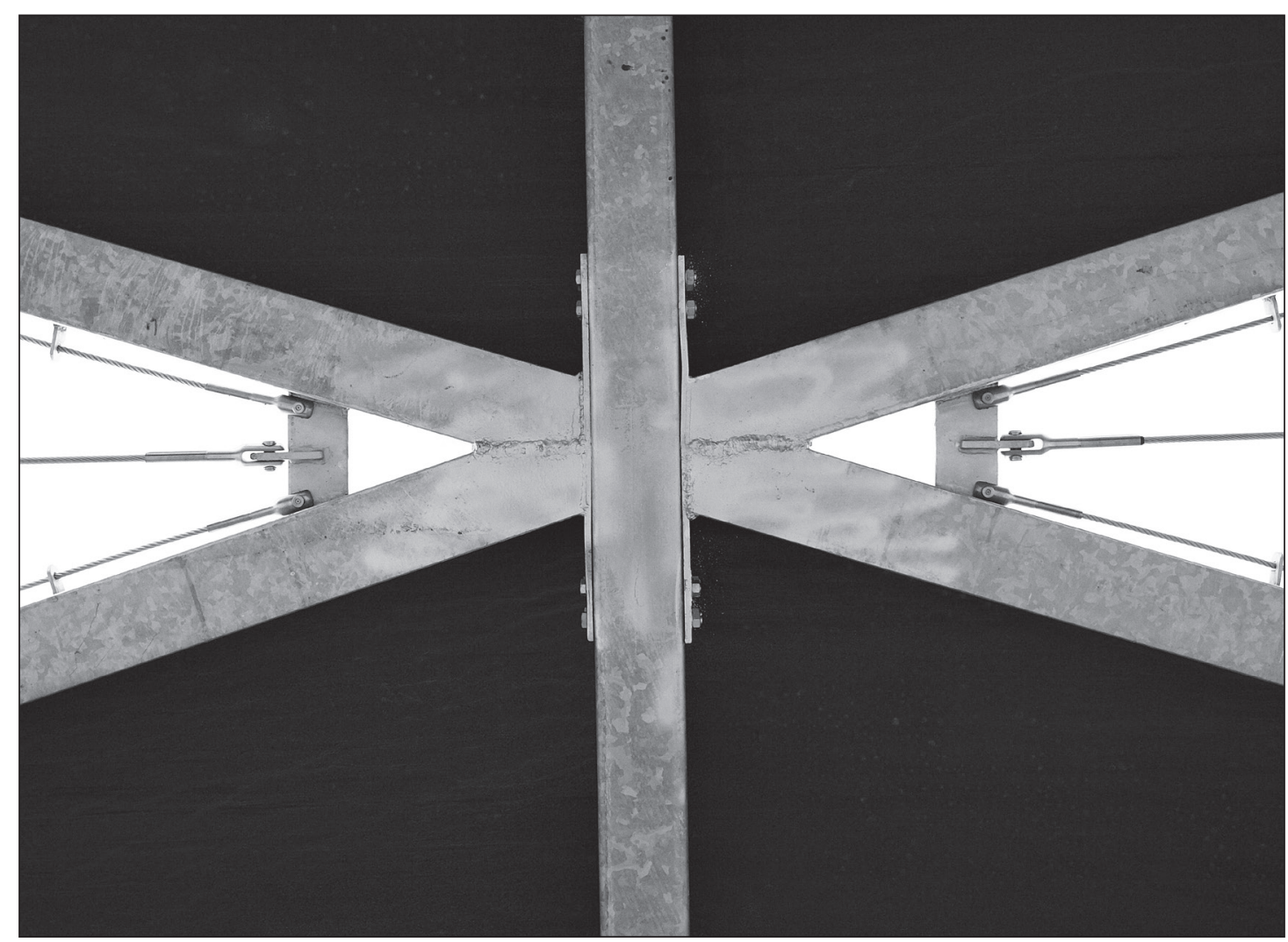

Fig. 7. Detalle de la "clave" del módulo estructural, donde se aprecian los perfiles soldados en taller, el sistema de ensamblaje en obra mediante tornillería, y el anclaje de los tensores sobre los que se coloca la malla metálica.

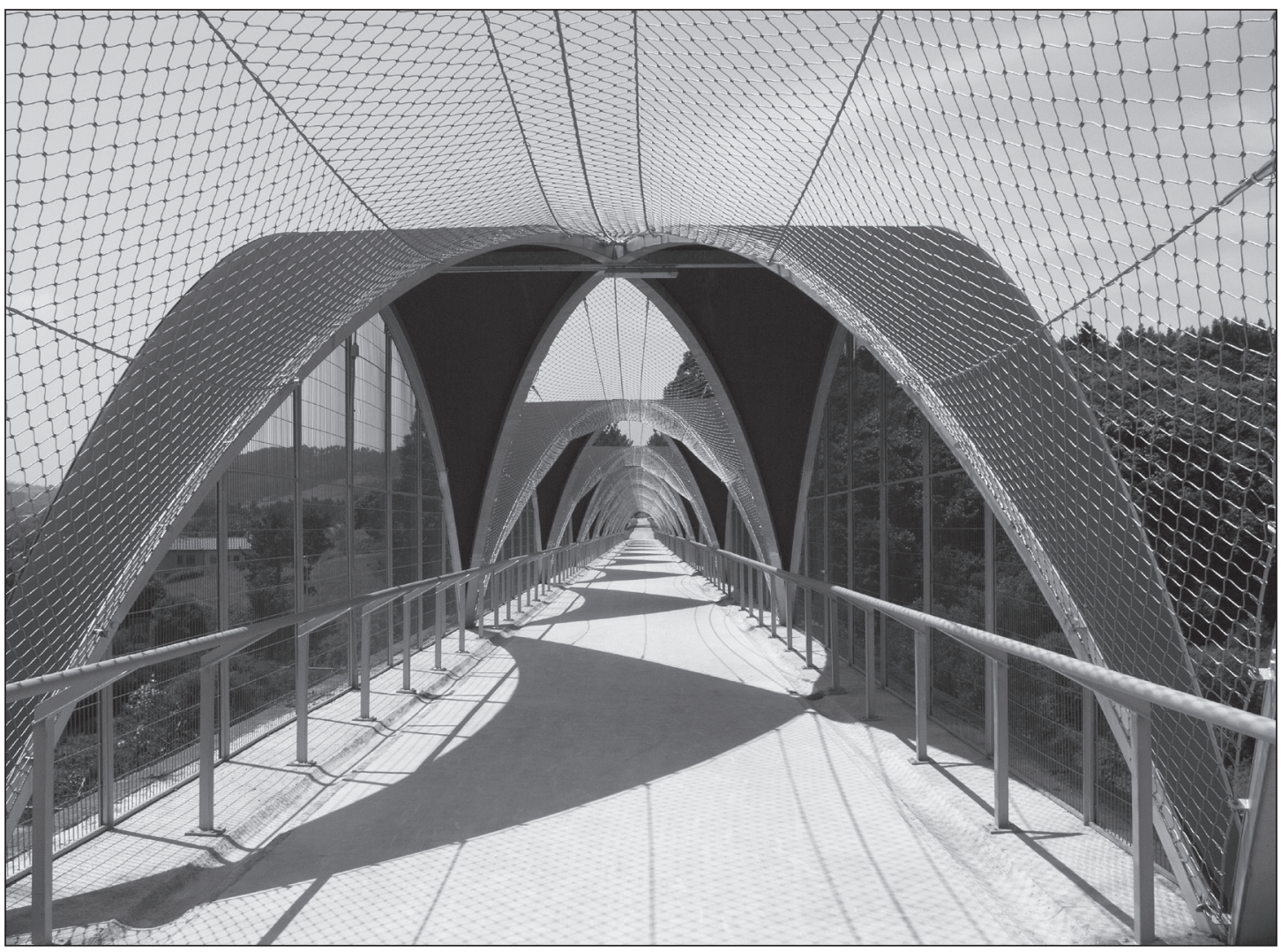

Fig. 8. Vista interior de la pasarela finalizada. 


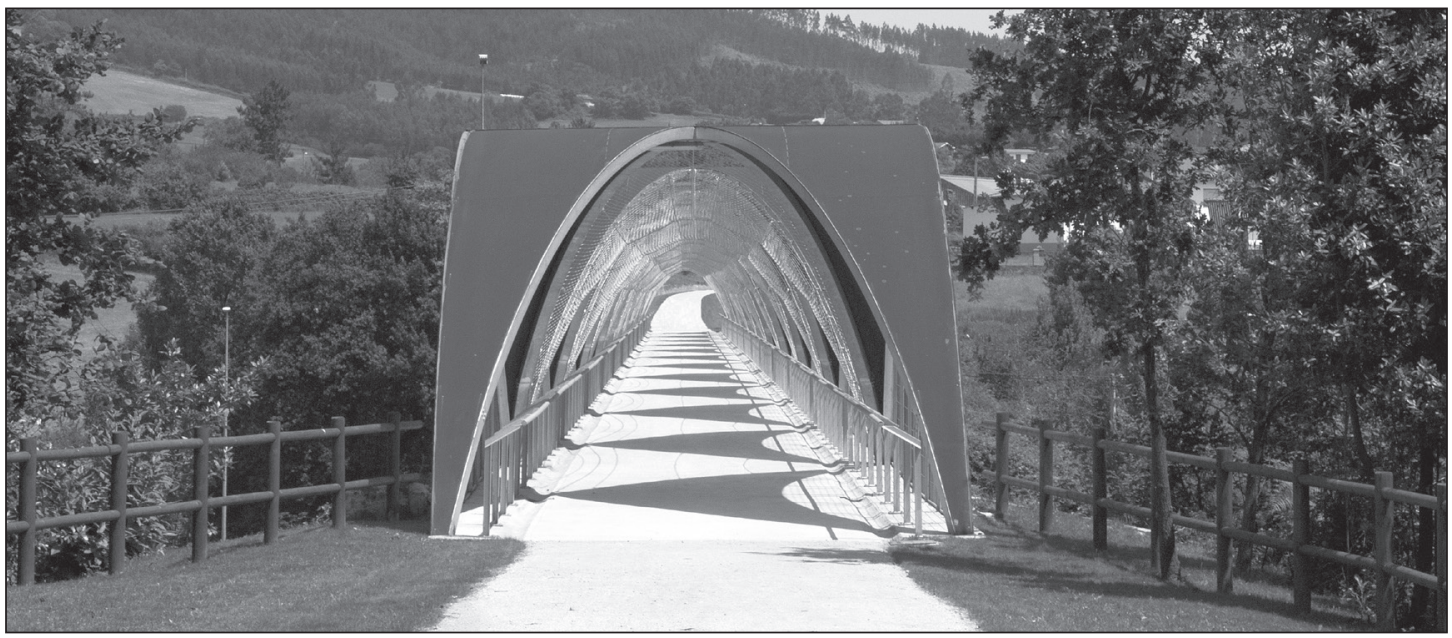

Fig. 9. Vista frontal de la pasarela desde la senda peatonal de la que forma parte.

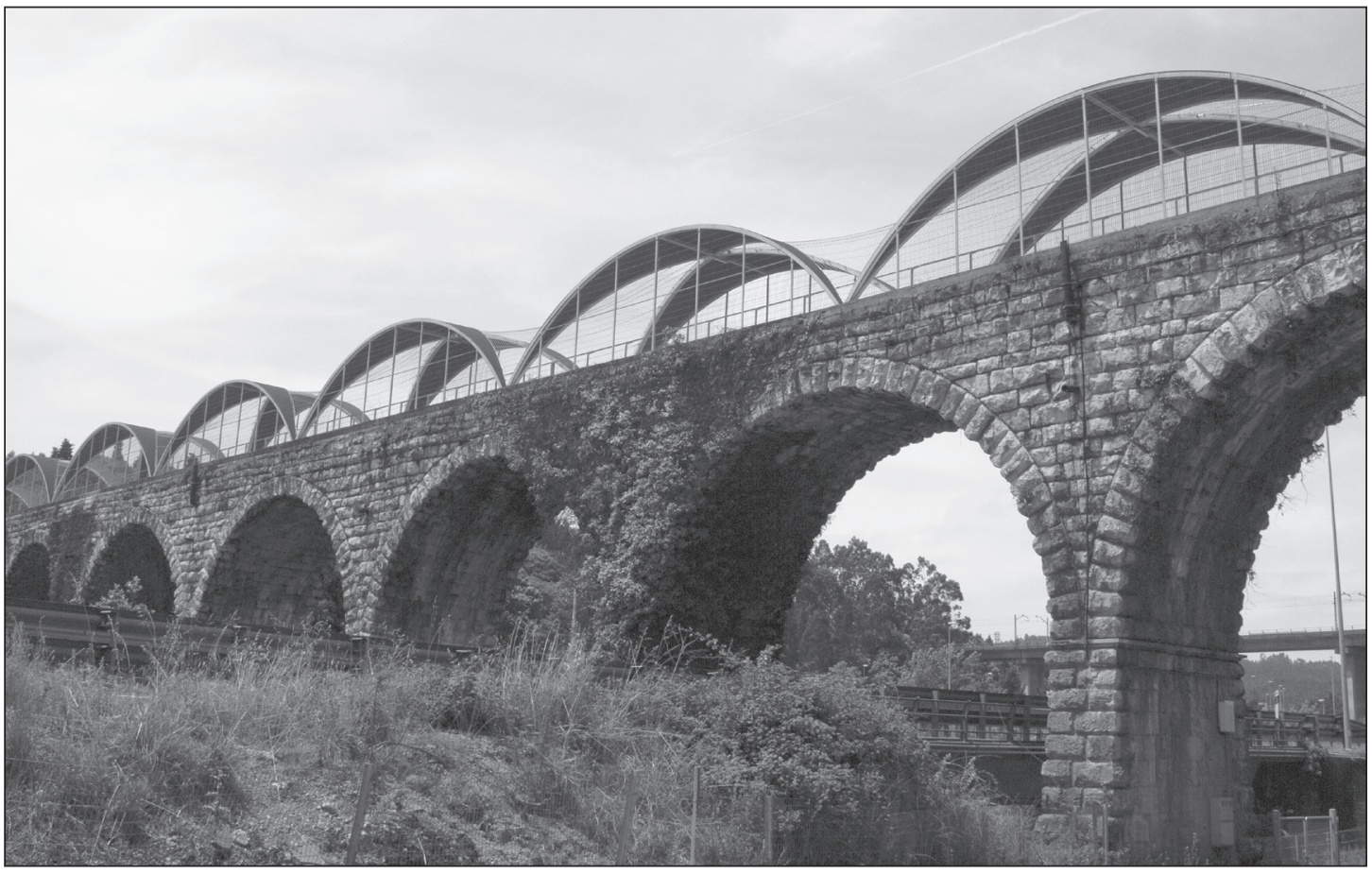

Fig. 10. Vista parcial del viaducto con la nueva pasarela peatonal desde la carretera AS-326.

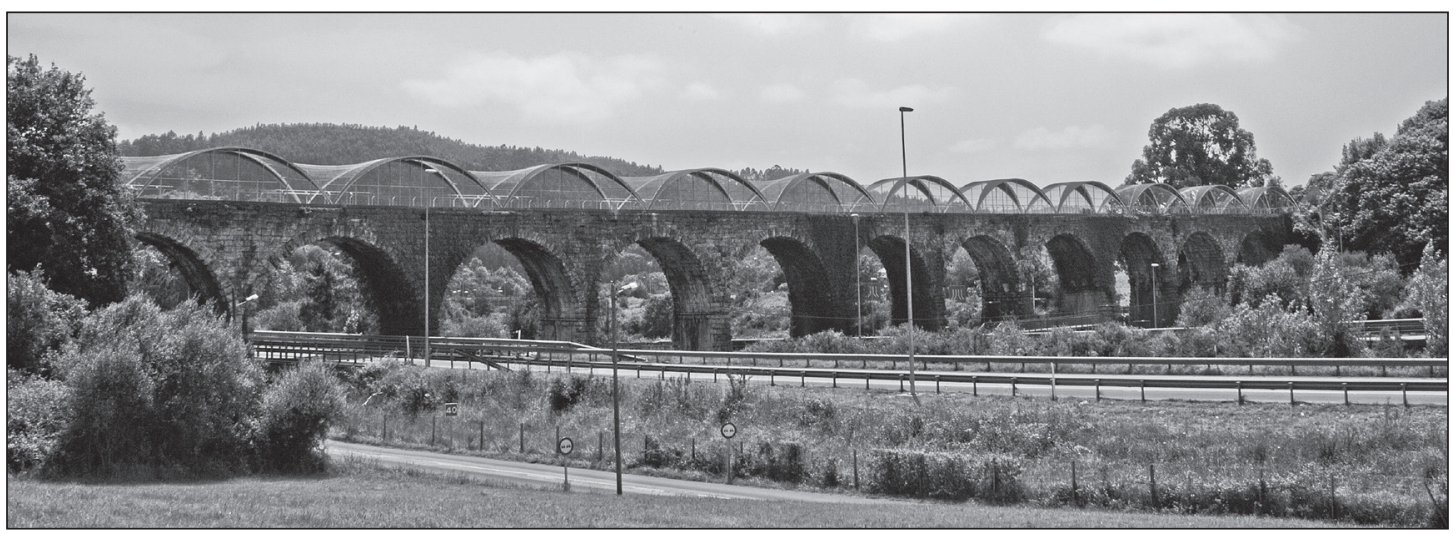

Fig. 11. Vista general del viaducto y la pasarela peatonal colocada sobre él. 